\title{
Training service providers increases TB screening in postnatal care
}

Population Council

Follow this and additional works at: https://knowledgecommons.popcouncil.org/departments_sbsr-rh

Part of the Health Policy Commons, Infectious Disease Commons, International Public Health Commons, Maternal and Child Health Commons, and the Public Health Education and Promotion Commons How does access to this work benefit you? Let us know!

\section{Recommended Citation}

"Training service providers increases TB screening in postnatal care," APHIA II Operations Research Project in Kenya OR Summary. Nairobi: Population Council, 2010. 


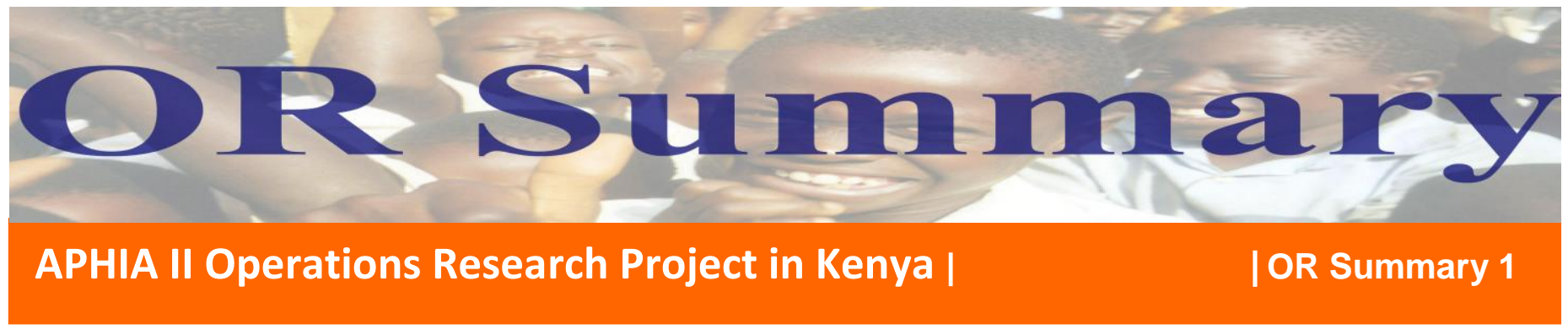

\section{Training service providers increases TB screening in postnatal care}

Key Finding: A significant increase in TB screening for women seeking postnatal services has been achieved through training serve providers and giving them a screening checklist. An Operations Research study found that $66 \%$ of clients were screened for at least one of the five cardinal symptoms of TB during the PNC consultation, compared to only $4 \%$ at the beginning of the intervention. However, only $21 \%$ of the clients were screened for all five tracer signs and symptoms.

Background: In Kenya, tuberculosis is considered a serious public health threat. It is estimated that incidence of the disease has increased almost tenfold over the last 20 years due to the HIV/AIDS pandemic, overcrowding in slum dwellings, and limited access to health services for a majority of the population. Indeed, Kenya is ranked $13^{\text {th }}$ among the 22 countries with the highest burden of TB, and which contribute to about $80 \%$ of the world's cases.

TB affects women in the reproductive years, and people living with HIV more than any other group. Undetected and untreated TB infection in a person living with HIV+ can lead to severe illness and death. Babies born to mothers with tuberculosis and HIV co-infection have higher rates of prematurity, low birth weight, and intrauterine growth restriction. In resource-poor settings, mother-tochild-transmission of tuberculosis is 15 percent within 3 weeks of birth. TB detection and treatment is therefore important in curbing these negative outcomes.

Integration of TB and HIV screening and treatment into reproductive health services offers an opportunity to increase access to these services for those most affected, and promotes early care seeking and treatment adherence. In Kenya, TB control activities have been integrated into antenatal care services as part of the focused antenatal care package. A study ${ }^{1}$ by the Population Council in 2008 found a $43 \%$ increase in the number of clients screened for TB in ANC clinics after integration. However, these services have not been extended to clients seeking post-natal care, including HIV-positive mothers and their babies. This is partly because current postnatal care practices only emphasise identification of danger signs or disease related to child-birth.

The research project: In the last two years, APHIA II Operations Research Project has collaborated with the Ministry of Health to develop and pilot-test an intervention to improve TB screening, case detection, treatment and care among postnatal clients. The intervention was implemented in five facilities in Nairobi Province over six months (February - July 2010), and included the following:

- Training service providers on prevention, control, detection and management of TB for the mother and baby during the post-partum period and providing supportive supervision to the facilities. A new module on TB screening in postnatal services was developed and used in the training, and a job aid/screening checklist provided. The five-day training programme also included a half-day session in a facility for hands-on practice for the trainees. Ninety-two providers in the five facilities were trained in the intervention. The module has now been incorporated in the Ministry of Health's existing postnatal training package for service providers.

- Reorganizing client flow to facilitate easier access for clients to PNC and TB screening;

- The Facilities were also given a monthly monitoring tool to strengthen data management during PNC.

\footnotetext{
${ }^{1}$ Mwangi A, D Waswa and C Warren. Integrating Tuberculosis Case Finding and Treatment into Focused Antenatal Care in Kenya.
} Population Council, April 2008. 
Findings of the evaluation: A significant increase in TB screening for postnatal women was noted when the intervention was evaluated after six months - $66 \%$ of clients were screened for at least one of the five cardinal symptoms of TB during the PNC consultation, compared to only $4 \%$ at baseline. However, only $21 \%$ of the clients were screened for all five tracer signs and symptoms.

Other key findings include the following:

- Improved TB case management, but very low numbers: Of 12,604 PNC clients screened for TB in the six-month period, only $15(0.11 \%)$ were suspected to have TB, based on the screening tool. Twelve of these were confirmed on laboratory diagnosis and put on treatment.

- Improved quality of care: During the intervention period, the quality of care provided in the integrated PNC and TB services improved significantly. A comparison of baseline and endline findings showed significant improvements on all 10 components of PNC: history taking; obstetric history taking; counselling on maternal danger signs; counselling on neonatal danger signs; physical observation and examination; counselling and testing for STI and HIV; mother's self care; FP counselling; continuity of care; and TB screening

Implications of the findings: This intervention demonstrated that it is feasible to use PNC services as a platform to increase TB screening and case detection - with minimal inputs, it is possible to train PNC providers and have them provide TB screening. Training providers, giving them job-aids, and strengthening client flow within the facility also improved the overall quality of care that the clients received.

However, the actual number of cases detected to have TB was extremely low, even though the five facilities chosen for the intervention are areas where TB prevalence is expected to be high. These findings compare to the previous study by Population Council in Western Kenya, which showed that although integrating TB screening into focused antenatal care increased the quality of care, detection of actual TB cases was extremely low. Of 11,418 women attending ANC services who were screened for TB in 2007, only two (2) were found to have TB. The results indicate that TB incidence might be negligible among the maternal and child health population. As a result, it is important for program managers and policy makers to decide whether routine TB screening in $\mathrm{RH}$ services is justifiable, and whether it needs to be scaled up.

It is hoped that the Ministry of Health and stakeholders in TB control will use these findings to explore whether linking TB services with RH services is necessary before full scale-up of this and similar interventions.

\section{Resources Available}

1. Training module: Integrating Tuberculosis screening in postnatal period

2. Job Aid: Screening for TB

3. Template for monthly monitoring of PNC and TB data at health facility

4. Research reports:

- Ndwiga, Charity, H Birungi et al. Integrating Tuberculosis Case Finding and Treatment into Postnatal Care. Population Council, February 2011

- Mwangi A, D Waswa and C Warren. Integrating Tuberculosis Case Finding and Treatment into Focused Antenatal Care in Kenya. Population Council, April 2008

\section{For more information, contact:}

Project Director

APHIA II OR Project in Kenya

Population Council

General Accident House

Ralph Bunche Road

PO Box 17643-00500, Nairobi, Kenya

Tel: +254 $202173480 / 1 / 2 / 3$

Fax: +254202173479

hbirungi@popcouncil.org

www.popcouncil.org

\section{Population Council}

(C) 2010 The Population Council, Inc. 